Silva et al., Revista Brasileira de Higiene e Sanidade Animal (v.1, n.2) p. 37 - 43, jul - dez (2007)

http://dx.doi.org/10.5935/1981-2965.20070008

www.higieneanimal.ufc.br

Artigo Cientifico

Medicina Veterinária

\title{
Fitoterápicos no Controle de Endoparasitoses de Caprinos e Ovinos ${ }^{1}$
}

\section{Herbal medicines in Endoparasitoses Control Goats and Sheep 1}

\author{
Luís Vieira da Silva $*^{2}$
}

${ }^{1}$ Palestra no 1 Simpósio de Higiene e Sanidade Animal em Ovinocaprinocultura na UECE

${ }^{1}$ Embrapa Caprinos, Estrada Sobral-Groaíras, km 4, Sobral, CE, 62.011-970.

\begin{abstract}
Resumo: Com base na dinâmica populacional dos endoparasitas no rebanho e na pastagem, têm sido desenvolvidos programas estratégicos de controle para regiões áridas e semi-aridas, que consistem em concentrar as vermifugações na estação seca, visando eliminar o parasitismo dos animais e, principalmente, prevenir a contaminação ambiental pelas fases de vida livre, na próxima estação chuvosa. O programa estratégico tem o objetivo de controlar os endoparasitas no rebanho quando eles estão em menor número na pastagem, isto é, na época seca. Em outros ecossistemas, o controle estratégico de vermifugação deve ser ajustado em consonância com as condições climáticas de cada região, procurando sempre concentrar a vermifugação no período seco. Em Unidades Demonstrativas conduzidas em áreas de Assentamentos do Programa de Reforma Agrária no estado do Ceará, a adoção do programa estratégico de controle de verminose mostrou claramente um impacto positivo sobre a produção de carne, quando comparada com o grupo controle.
\end{abstract}

Palavras chave: estratégia, parasitismo, rebanho

Abstract: Based on the parasites' population dynamic, while acting on animal groups and "its feeding, several programs have been created in order to control specific regions, which concentrates the "vermifugações" during the dry station, trying to eliminate the animals' parasites, and, most of all, prevent any environmental contamination through their free lives seasons, on the next rainy season. These strategical programs intend to control the parasites among groups of animals, while they are in a low number, which happens during the dry season. This same control, in another ecosystems, must be adjusted to the weather conditions of each region, intending to always concentrate the "vermifugação" on the dry season. In Demonstratives Units leaded by "Assentamentos do Programa de Reforma Agrária no estado do Ceará" areas, the usage of this program has clearly shown a positive impact on the meat production, once compared to the control group.

Key-words: strategy, parasitism, flock

Autor para correspondência. E-mail: *1vieira@cnpc.embrapa.br

Recebido 20/02/2007; Aceito 28/06/2007 


\section{Introdução}

A exploração de caprinos e ovinos é uma atividade largamente explorada nos países tropicais para a produção de carne, leite e peles. Em Unidades de Produção Familiar, os pequenos ruminantes constituem a principal fonte protéica e de geração de renda dos agricultores e de suas famílias. Entretanto, as endoparasitoses constituiem-se num dos principais fatores limitantes para a produção desses animais, especialmente nas regiões tropicais, onde os prejuízos econômicos são mais acentuados. Embora, pesquisadores, técnicos e produtores tenham consciência que as endoparasitoses gastrintestinais constituam um entrave de grande importância na cadeia produtiva de caprinos e ovinos, as perdas produtivas não tem sido quantificadas. Apesar do desconhecimento dos reais prejuízos, são freqüentes os relatos de morbidade e mortalidade de animais, cujos sintomas clínicos descritos definem um quadro clínico típico de verminose. Em adição, despesas financeiras adicionais são geradas com a aquisição de drogas antiparasitárias e aumento de mão de obra. O custo com a compra de anti- helmínticos no mundo cresce vertiginosamente, haja visto que conforme ANTUNES (1991), o faturamento com a venda de antihelmínticos no ano de 1990 no Brasil foi da ordem de 100 milhões de dólares, entretanto, trabalho publicado por MOLENTO (2004), mostra que o comércio com estes produtos no País já alcança $42 \%$ de um volume de vendas de 700 milhões de dólares anuais, equivalente a um montante de 294 milhões de dólares/ano. A venda mundial de produtos veterinários é de 15 bilhões de dólares anuais, sendo que 27\% (4,05 bilhões) é representado por parasiticidas (MOLENTO, 2004).

\section{Resistência anti-helmíntidca e presença de resíduos químicos nos alimentos}

Devido à falta de conhecimento básico no que se refere à biologia e à epidemiologia dos endoparasitos, associada ao custo extremamente elevado dos insumos químicos, a maioria dos produtores não adota o programa estratégico de controle recomendado, nem realiza anualmente, de forma racional, a alternância dos grupos 
Silva et al., Revista Brasileira de Higiene e Sanidade Animal (v.1, n.2) p. 37 - 43, jul - dez (2007)

químicos utilizados. $\mathrm{Na}$ maioria das vezes, as vermifugações são realizadas sem base técnica e com isso, os nematódeos rapidamente desenvolvem resistência às drogas disponíveis no mercado. Outro fator agravante é que o controle estratégico, em curto prazo, proporciona excelentes resultados, entretanto, quando utilizado por período prolongado (mais de cinco anos), toda a população de parasitas, poderá se tornar resistente. A resistência anti-helmíntica é considerada atualmente um dos principais entraves para o sucesso dos programas estratégicos de controle de verminose em caprinos e ovinos e, consequentemente, interfere diretamente na produção animal. É importante considerar que em rebanhos onde há problemas de resistência anti-helmíntica, o prejuízo econômico ocasionado pela verminose é mais acentuado, uma vez que, além da queda na produtividade do rebanho, os custos de produção são onerados em função da aquisição de insumos químicos ineficazes pela presença de resistência parasitária. Dessa forma, a vermifugação dos rebanhos de forma pouco criteriosa associada a resistência anti-helmíntica, tendem a comprometer, muito em breve, o controle de verminose, pela extinção das fontes de controle químico, com sérias consequências para a produção animal. Além disso, o uso de insumos químicos e processos de produção não naturais, têm sido cada vez mais questionados, já que os antiparasitários deixam níveis consideráveis de resíduos na carne, no leite e no meio ambiente, que poderão interferir na saúde humana, efeitos estes só aparentes após o uso considerável. Em algumas situações, os resíduos poderão entrar na cadeia alimentar humana, podendo ocasionar problemas de saúde (PADILHA et al., 2000). Considerando a importância dos endoparasitos gastrintestinais na produção de caprinos e ovinos, bem como os problemas acima apontados, no que diz respeito a resistência antihelmíntica, a presença de resíduos químicos nos alimentos e no meio ambiente, além dos aspectos econômicos referentes aos custos dos vermífugos, torna-se necessário o desenvolvimento de estudos que visem a busca de outras alternativas complementares aos métodos tradicionais, que sejam de baixo custo e menos prejudiciais à saúde humana e ao desequilíbrio ambiental. A produção agroecológica surge como uma 
Silva et al., Revista Brasileira de Higiene e Sanidade Animal (v.1, n.2) p. 37 - 43, jul - dez (2007)

alternativa, não só em termos de recuperação da Unidade Produtiva, mas, também, para a valorização econômica dos alimentos produzidos, se constituindo numa demanda diferenciada na definição de prioridades de pesquisa e desenvolvimento do País. Este aspecto é de fundamental importância, em virtude da pressão cada vez maior por parte dos consumidores por alimentos isentos ou com o mínimo de resíduos químicos.

\section{Fitoterapia no controle de verminose}

A fitoterapia no controle de verminose é uma alternativa que poderá reduzir o uso de anti-helmínticos e prolongar a vida útil dos produtos químicos disponíveis.

Entretanto, na Medicina Veterinária, ao contrário do que ocorre na Medicina Humana, estudos envolvendo produtos fitoterápicos para o controle de doenças ainda são escassos. Muitas plantas são tradicionalmente conhecidas como possuidoras de atividade anti-helmíntica, necessitando, entretanto, que seja comprovada cientificamente, suas eficácias.

\section{IDRIS \& ADAM (1982),} observaram redução da sintomatologia clínica de hemoncose em caprinos medicados com Artemisia herba-alba, entretanto, a presença de ovos nas fezes não foi suprimida totalmente. No Brasil, OLIVEIRA et al., (1997), observaram redução da carga parasitária por nematódeos gastrintestinais em caprinos que receberam diariamente folhas de bananeiras por um período de 25 dias, quando comparados com o grupo controle. A eficácia da folha de bananeira foi de $57,1 \%$ para Haemconhcus $\quad s p, \quad 70,4 \%$ para Oesophagostomum sp, $65,4 \%$ para Trichostrongylus sp e de 59,5\% para Cooperia sp.

No estado do Piauí foram listadas por GIRÃO et al., (1998), com base em informações de produtores de caprinos, 14 plantas como possuidoras de atividade anti-helmíntica.

As plantas relacionadas foram: Cucurbita moschata (Abóbora), Luffa operculata (Bucha paulista, Cabacinha), Operculina sp. (Batata de-purga), Heliotropium sp. (Crista de galo), Mentha sp. (Hortelã), Carica papaya (Mamoeiro), Chenopodium ambrosioides (Mastruço), Momordica charantia (Melão de são caetano), Milome (nome científico não identificado), Plumeria $s p$ (Pau de leite, Janguba), Jatropha curcas (Pinhão-branco, Pinhão-de purga), 
Silva et al., Revista Brasileira de Higiene e Sanidade Animal (v.1, n.2) p. 37 - 43, jul - dez (2007)

Scopalaria dulcis (Vassourinha) e Croton $s p$ (Velame).

MENEZES et al. (1992) avaliaram a atividade ovicida in vitro de folhas e sementes de quatro leguminosas sobre H. contortus de caprinos. As sementes apresentaram resultados satisfatórios. VIEIRA et al. (1999) avaliaram a eficácia anti-helmíntica de nove plantas sobre Haemonchus contortus em caprinos. Entre as plantas testadas, a Anona squamosa e a Momordica charantia, reduziram o número de vermes adultos respectivamente, em $30,4 \%$ e $17,6 \%$. BATISTA et al. (1999) observaram que a Momordica charantia e spigelia anthelmia inibiram o desenvolvimento de ovos e imobilizaram larvas de $H$. contortus.

Estes resultados foram confirmados por ASSIS (2000), que demonstraram ainda atividades ovicida e larvicida dos extratos acetato de etila e matanólico em nematódeos gastrintestinais de caprinos.

PESSOA (2001) observaram atividade ovicida in vitro de óleos essenciais das plantas Chenopodium ambrosioides, Ocimum gratissumum, Lippia sidoides e Croton zehntneri, bem como da azadiractina, princípio ativo da Azadirachta indica (neem) sobre $H$. contortus de caprinos.

\section{Conclusões}

A comprovação experimental da eficácia de fitoterápicos no controle de endoparasitos de caprinos e ovinos bem como a implementação de outras alternativas não químicas de controle, deverá reduzir o número de vermifugações anuais. Com isso, a pressão anti-helmíntica sobre os nematódeos gastrintestinais irá reduzir, prolongando a vida útil dos composto químicos e a redução de resíduos químicos nos alimentos de origem animal. Além dos fitoterápicos, outras alternativas poderão auxiliar no controle da verminose dos pequenos ruminantes. Dentre estas, destacam-se a identificação de animais resistentes, a avaliação de medicamentos homeopáticos e o controle biológico através de fungos nematófagos predadores de ovos e larvas dos nematódeos no meio ambiente.

\section{Referências Bibliográficas}

ANTUNES, N.A indústria veterinária no Brasil. Comportamento do mercado em A Hora Veterinária, v.62: p.27-33, 1991. 
Silva et al., Revista Brasileira de Higiene e Sanidade Animal (v.1, n.2) p. 37 - 43, jul - dez (2007)

ASSIS, L.M. de. Atividade antihelmíntica in vitro de extratos de Spigelia antehlmia sobre Haemonchus contortus. 2000. 44f. Dissertação (Mestrado em Ciência Veterinárias) - Faculdade de Medicina Veterinária. UECE, Fortaleza.

BATISTA, L.M.; BEVILÁQUA, C.M.L.; MORAES, S.M.; VIEIRA, L.S. In vitro ovicidal and larvicidal effect of the plants Spigelia anthelmia and Momordica charantia agains Hameonchus contortus. Ciência Animal, v.9, n.2, p.67-74, 1999.

GIRÃO, E.S; CARVALHO, J.H. DE; LOPES, A.S.; MEDEIROS, L.P.; GIRÃO, R.N. Avaliação de plantas medicinais com efeito anti-helmintico para caprinos. Teresina: Embrapa MeioNorte, 1998. 9p. (Embrapa Meio-Norte. Pesquisa em andamento, 78).

IDRIS, U.E.A.A.; ADAM, S.E.I. The anthelmintic efficacy of Artemisia herbaalba against Haemonchus contortus infection in goats. Natl. Insti. Anim. Health Q. (Jpn.), v.22, p.138-143, 1982.
MENEZES, R.C.A.A; VIEIRA, L.S.; CAVALCANTE, A.C.R.; CAVADA, B.S.; OLIVEIRA, J. T.; MOREIRA, R.A. Estudos preliminares in vitro da atividade ovicida de folhas e sementes de quatro leguminosas sobre Hameonchus contortus de caprinos. Arquivos da Universidade Federal Rural do Rio de Janeiro, v.15, n.2, p.121-127, 1992.

MOLENTO, M.B.; TASCA, C.; GALLO, A.; FERREIRA, M.; BONONI, R.; STECCA, E. Método Famacha como parâmetro clínico individual de infecção por Haemonchus contortus em Pequenos ruminantes. Ciencia Rural. v. 34, p.11391145, 2004.

OLIVEIRA, D.B.; AMORIM, A.; BRAGA， M.M.; MATTOS; D.G.; ALMOSNY, N.R.P. Atividade antiHelmíntica da babaneira (Musa sp) em caprinos. In: Congresso Brasileiro de Parasitologia, 15., 1997. Salvador, BA. Anais... Salvador: Sociedade Brasileira de Parasitologia, 1997. p.65. 
Silva et al., Revista Brasileira de Higiene e Sanidade Animal (v.1, n.2) p. 37 - 43, jul - dez (2007)

PADILHA, T.; MARTINEZ, M.L.;

GASBARRE, L.; VIEIRA, L.S. Genética:

a nova arma no controle de

doenças. Balde Branco, v.36, n.229, p.58, jul. 2000.

VIEIRA, L.S.; CAVALCANTE, A.C.R.;

PEREIRA, M.F.; DANTAS, M.F.;

XIMENES, L.J.F. Evaluation of

anthelmintic efficacy of plants avaivable in Ceará State, Northeast Brazil, for the control of goat gatrointestinal nematodes. Revue Méd. Vet., v.150, n.5, p.447-452, 1999. 